\title{
[REESCRIBIENDO HISTORIAS: PARA UN CATÁLOGO DE LA PRODUCCIÓN LITERARIA DE JERÓNIMO MORÁN PUBLICADA EN PRENSA]
}

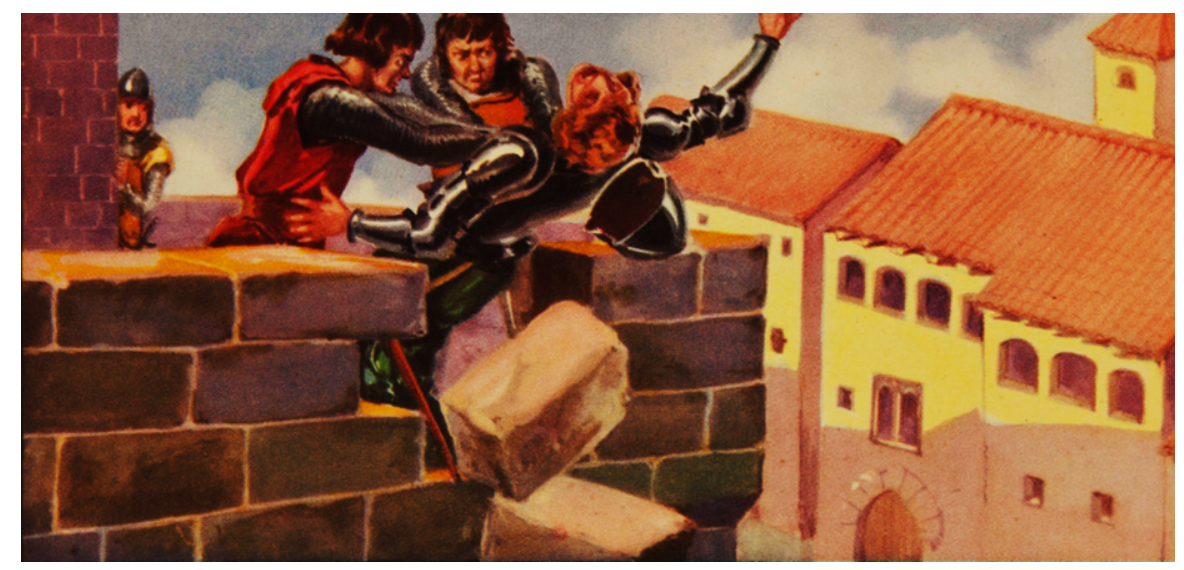

Repetidas veces se unieron en conspiración algunos cortesanos para quitar la vida a don Álvaro de Luna y al ver burlados por él sus planes les acuciaba y dolía más, impulsándoles con mayor ardor al asesinato. Guiado por la opinión de los grandes, el pueblo odiaba también al condestable y, acusándole de haber embrujado el ánimo del rey para sus fines, pedía su cabeza. Cierto día, en Burgos, el sacerdote, desde el púlpito, hizo alusiones contra el condestable... En la torre de su castillo, en conversación con su fiel servidor Rivadeneira, supo don Álvaro, por este, que un tal Alfonso Pérez de Vivero era el cabeza de la conspiración. (Cromos culturales. Don Álvaro de Luna, Barcelona: Barsal, I 930-I 940, tarjeta VI).

A la hora fablole el buen maestre disciéndole: "Por cierto cosa debida es, pues por quantos caminos e amonestamientos yo vos he fecho non vos avéis querido apartar de vuestras maldades que contra mí avéis ordido e 
amasado, que se cumpla en vos lo que vos juré delante de Fernando, que está aquí presente”. Esto así fablado por el maestre, luego mandó a Juan de Luna e a Fernando de Rivadeneyra: "Que tomasen a aquel su malvado e perverso traidor criado e lo echasen de las barandas de la torre abaxo". Lo cual ellos pusieron sin tardanza alguna por obra. (Crónica de don Álvaro de Luna, Madrid: Sancha, I784, p. 309). 


\title{
REESCRIBIENDO HISTORIAS: PARA UN CATÁLOGO DE
}

\section{LA PRODUCCIÓN LiteraRia DE JERÓNIMO MORÁN \\ PUBLICADA EN PRENSA ${ }^{\text {I }}$}

\author{
María Ceide Rodríguez \\ Universidade de Vigo
}

Title: Rewriting stories: for a Catalog of the Literary Production of Jerónimo Morán Published in Press

\begin{abstract}
Jerónimo Morán Martín, politician and intellectual laureate of Spanish Romanticism barely known today, composed throughout his life a large number of titles of very varied nature that today remain, mostly, forgotten by critics and scattered in periodicals of the time. This work aims to publicize the extensive poetic, narrative and essay production of an author who achieved very young success thanks to a drama centered on the romantic rewriting of the Middle Ages, Los cortesanos de don Juan II, and whose literary career led him to found a magazine and contribute with the talent of his pen to the consolidation of the nineteenth-century journalism.
\end{abstract}

Key words: Morán. I gth century. Romanticism. Press.

El convulso XIX es el siglo en el que la prensa escrita alcanza en España un desarrollo exponencial que le permite convertirse en punto de referencia indiscutible como medio de comunicación de masas y de expresión ideológica (Alonso Seoane, 2004: Io-53). La libertad de imprenta, aprobada por las Cortes de Cádiz el veintiséis de octubre de I 8 I 2, favorece la multiplicación de publicaciones, especialmente las de tinte político, y al abrigo de este nuevo panorama periodístico los escritores españoles comienzan muy pronto a colaborar en alguna, o varias, de las múltiples revistas que proliferan en la época publicando textos con relativa frecuencia. ${ }^{2}$ Conscientes del creciente poder y prestigio de los diarios en lo que a difusión de ideas políticas, culturales y religiosas se refiere, importantes nombres del Romanticismo hispano, como Mariano José de Larra, Manuel Bretón de los Herreros

${ }^{\mathrm{I}}$ Este trabajo se inserta en el ámbito investigador del proyecto FFI-20 I 5-64 IO7-P (MINECO/FEDER, UE).

${ }^{2}$ Tras diez días de intenso debate, las Cortes, en votación nominal, aprobaron por una mayoría de 68 votos contra 52 una moderna ley de imprenta desarrollada en veinte puntos que daba derecho de impresión a cualquier ciudadano (Rico y Amat, I 860: 230). 
o Ramón de Mesonero Romanos, inician una intensa labor periodística y participan en el auge decimonónico de la prensa con escritos de creación literaria y con artículos de opinión con los que dan a conocer al público su posicionamiento en relación con diferentes temas de actualidad económica, social y de gobierno. Jerónimo Morán Martín (Valladolid, i I de marzo de I 8 I7; Madrid, 2 I de diciembre de I 872) forma parte de este nutrido grupo de periodistas e intelectuales.

Miembro de los principales círculos de erudición de la época, este autor, apenas conocido hoy en día, desarrolla en su momento una intensa labor cultural que le proporciona un considerable éxito y reconocimiento público. De su vida privada poco se sabe. Vallisoletano de nacimiento, en r 835 ingresa en la Academia de Letras Humanas de la Universidad de Valladolid (M.H.C., I 873: 50). Allí entabla relaciones con Pedro de Madrazo, Miguel de los Santos Álvarez, Manuel de Assas o José Zorrilla y con ellos, entre otros, contribuye al afianzamiento del incipiente Romanticismo español. Durante su etapa universitaria inicia su actividad como escritor. En esta época compone sus primeros versos que da a conocer a través de la prensa y también de los certámenes y coloquios celebrados en la propia Universidad (Alonso Cortés, i 91 4: 57). Entre estos textos, muchos de ellos encargos de su maestro y mentor, el catedrático de poética don Lorenzo Arrazola (M.H.C., I 873: 50), destacan A Florinda, Zaida y Gonzalo, Las Catacumbas y el romance morisco Zulma (Alonso Cortés, I914: 9). A estos escritos, y a otros, me referiré en las páginas que siguen.

Poco a poco, Morán despierta y desarrolla su interés por la política y, sobre todo, por la literatura, ámbito en el que pronto comienza a cosechar importantes éxitos. Con apenas veinte años, en I837, es premiado con un rasgo épico por la Sociedad de Amigos del País de Salamanca gracias a uno de los textos que escribe sobre el sitio de Bilbao (Ribao Pereira, 2017). Así lo recogen diversas revistas nacionales, como Diario de Avisos 
de Madrid (1 4 marzo, i 839) y Eco del Comercio (27 febrero, I 839). ${ }^{3}$ Durante años compagina los cargos que desempeña en el Gobierno, en las áreas de Guerra, Hacienda y Fomento, con la abogacía y la literatura (Ribao Pereira, 2017). Realiza diversas colaboraciones en prensa y en I 867 funda $\mathrm{La}$ Guirnalda, una publicación quincenal de corte conservador orientada a un público eminentemente femenino al que trata de inculcar valores cristianos y de formar en principios basados en la religión y la familia, que dirigirá desde sus comienzos y desde la que presentará al público buena parte de su variada producción literaria (M.H.C. I 873: 5 I).

El teatro es el género que mayor éxito le depara en los inicios de su carrera. La nueva escuela teatral decimonónica que, frente a la inflexibilidad de la norma neoclásica, proporciona al dramaturgo una libertad creadora absoluta seduce a un Morán, todavía escritor novel, que con apenas diecisiete años compone Los cortesanos de don Juan II, un drama histórico romántico en cinco actos estrenado en Valladolid el 29 de diciembre de 1838 y por el que recibe innumerables elogios. La primera guerra carlista y el conflicto dinástico que enfrenta al hermano de Fernando VII y a su hija Isabel explican los alegatos liberales de esta obra ambientada en la corte de Juan II de Castilla, con la que el autor busca mostrar públicamente su rechazo al poder absolutista. La reescritura romántica de la Edad Media, práctica habitual en la literatura de este período, es rentabilizada, de este modo, por Morán para realizar una férrea defensa del liberalismo como única opción política válida. No en vano, la obra es llevada por primera vez a escena en una función benéfica en favor de los prisioneros del bando cristino tras la derrota sufri-

${ }^{3}$ Las noticias que aparecen en el Diario de Avisos de Madrid y Eco del comercio son muy similares y aportan la misma información: "El sitio de Bilbao: rasgo épico premiado por la sociedad económica de Salamanca; su autor don Gerónimo Morán. Se vende a 2 rs. En la librería de Escamilla". (Eco del comercio, 27 febrero i 839: 4); "El sitio de Bilbao: rasgo épico, premiado por la sociedad económica de Salamanca; su autor don Gerónimo Morán. Se vende a 2 rs. en la librería de Escamilla, calle de Carretas”. (Diario de Avisos de Madrid, I4 marzo I 839: 4). 
da frente al ejército de don Carlos en la zaragozana villa de Maella (Ribao Pereira, 2017: 652-653).

Aplaudido fundamentalmente, además de por este drama, por su Biografía de Miguel de Cervantes Saavedra (joya literaria incluida en una lujosa edición de $E l$ Quijote publicada en la época) ${ }^{4} \mathrm{y}$ por sus textos teatrales, entre los que se cuentan comedias (La ocasión por los cabellos) y zarzuelas (El paño de lágrimas), su producción poética, narrativa y ensayística continúa dispersa en las páginas de los periódicos de la época a la espera de algún tipo de atención crítica (Ceide Rodríguez, 2017: 24I).

En este trabajo pretendo llevar a cabo, precisamente, una breve aproximación a esta producción desconocida de Jerónimo Morán publicada en prensa. Prolífico e infatigable escritor, a lo largo de su vida, el autor vallisoletano compone una gran cantidad de textos que, difundidos a través de diferentes medios, dan testimonio de su innegable talento como literato y también de su amplia formación como humanista.

La historia es, tal vez, una de las ramas de conocimiento que cultiva con mayor ahínco. Su interés por el pasado más remoto le lleva a dedicar varios trabajos a pasajes de la historia egipcia y de la antigua Grecia; así, en el ensayo "Artemisa y el mausoleo" da cuenta de los esfuerzos de la "reina de Caria" por honrar la memoria de su marido con la construcción de un grandioso monumento fúnebre; y en el rasgo histórico "La tela de Penélope" aborda el simbolismo del lienzo tejido por la hermosa esposa de Ulises durante la ausencia del héroe. Pero no solo escribe el autor sobre la antigüedad clásica; la historia nacional reciente, desarrollada al abrigo del convulso devenir político decimonónico, llama también la atención de un Morán políticamente muy comprometido que publica diferentes artículos

${ }^{4}$ Volumen editado por José Gil Dorregaray en la Imprenta Nacional de Madrid entre los años i 862- I 863. Adornado con láminas de cobre y facsímiles de Cervantes, en su tercer tomo se incluye el trabajo de Morán elaborado a partir de un estudio anterior de Fernández de Navarrete (Rey Hazas y Muñoz Sánchez, 2006: 56). 
a propósito del pronunciamiento que a comienzos de siglo tiene lugar a las puertas del Palacio Real de Madrid, donde el pueblo castellano se levanta en armas contra las fuerzas invasoras del emperador Napoleón. Sobre este episodio versan los textos "A las víctimas del dos de mayo" y también "El dos de mayo de i 808 ".

Sin perder el hilo histórico, el autor publica "Doctrina de Salomón”, un documento constituido por una serie de lecciones en verso recomendadas por Real Decreto para la enseñanza en las escuelas de instrucción primaria y que ve la luz en cinco números consecutivos de La Guirnalda. La evidente voluntad didáctica y pedagógica con la que Morán elabora este texto está presente también en las fábulas "La ortiga, el niño, la flor", "Los animales con máscaras”, "La mujer y el tiempo", "Una fábula de Samaniego” y en algunos que otros artículos de difícil clasificación, como los que llevan por título "Una lección de ortografía" o "La orden de San Jorge o de la Jarretera". Mención aparte merece la sección “Antorcha de la fe”, un apartado propio en la revista en el que, previa aprobación de la autoridad eclesiástica, el autor desarrolla instrucción en materia religiosa a través de "breves nociones sobre historia sagrada”. Hombre de fe, sus inquietudes dogmáticas quedan reflejadas también en los numerosos textos que elabora con ánimo de ensalzar la figura de la Virgen ("Las flores de mayo. Himno dedicado a la virgen Nuestra Señora”, “A la Purísima Concepción de Nuestra Señora") o de homenajear diferentes celebraciones de tipo litúrgico y doctrinal (véanse "La festividad de la Candelaria”, "El mes de mayo", "Nacimiento de Jesucristo").

En cuanto a los artículos literarios, es posible distinguir en la producción de Morán dos grupos perfectamente diferenciados. Por un lado, destacan trabajos de creación en los que tienen cabida composiciones de muy 
variada forma y contenido: 5 romances ("Carnes-Tollendas), sonetos ("Los réprobos"), letrillas ("Perdona que no era a ti"), cuentos ("El baile de doña Aldegundis”), leyendas ("El guardapiés azul”) o epístolas (“A mi querido amigo el Sr. D. M. R.”). Por otro, cabe mencionar escritos relacionados con la vida y obra de autores coetáneos y también de épocas precedentes. En este apartado pueden incluirse la "Biografía de Fray Luis de León”, el artículo "Los últimos días de Cervantes" y, como no, la sección "Bibliografía”, en la que Morán se ocupa, principalmente, de reseñar libros de amigos y compañeros de profesión sobre los que trata de llamar la atención de sus lectoras (por ejemplo, "Corona de la infancia. Lectura poética y canciones para los niños, por la señorita Doña Blanca de Gassó y Ortiz”).

Nunca olvidó el director de La Guirnalda que las mujeres constituían mayoritariamente el grueso de su público. Específicamente para ellas escribió un tipo de artículos muy concreto centrado en la exposición de las virtudes y cualidades que posibilitan un correcto desempeño de las funciones de esposa, madre y ama de casa. De la educación de los hijos habla en

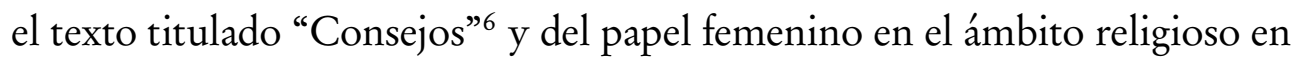
"La mujer dentro del cristianismo"; el decoro de las muchachas en fiestas y celebraciones protagoniza el trabajo "A nuestras lectoras" y el buen gusto en el vestir ocupa la crónica "Útiles advertencias".

En definitiva, en vista de la cantidad y variedad de títulos incluidos en este breve panorama, podría afirmarse que Jerónimo Morán cultivó toda clase de géneros literarios. Considerado uno de los mejores dramaturgos de su tiempo, ${ }^{7}$ su producción artística es muy variada y, además de teatro, abar-

\footnotetext{
${ }^{5}$ Cito un único ejemplo para cada uno de los tipos señalados y remito, para la bibliografía completa al respecto, al catálogo con que cierro estas páginas.

${ }^{6}$ Texto inicial del número con el que la publicación se estrena en el panorama periodístico decimonónico en I 867.

${ }^{7}$ La España Moderna (marzo I 91 3) publica en uno de sus números un artículo en el que, entre otros temas, trata de la delicada situación del Teatro del Príncipe en el período comprendido entre i 840 y i 849; el texto habla del bajo número de estrenos que se representan
} 
ca lírica y narrativa. Como en el caso de muchos de sus coetáneos, la difusión de sus textos y su reconocimiento público como escritor se vieron, sin ninguna duda, favorecidos por la eclosión de la prensa escrita a la que, tras la muerte de Fernando VII, el Romanticismo dio cabida definitivamente. A pesar del impulso periodístico, el autor vallisoletano no gozó, sin embargo, del éxito y la fama posterior que sí obtuvieron autores románticos tan laureados como el duque de Rivas, Antonio Trueba o José de Espronceda. A juzgar por lo prolijo de su producción, tal vez sea conveniente plantearse la necesidad de llevar a cabo un estudio más detallado de sus textos en futuros trabajos de investigación literaria decimonónica.

Reproduzco a continuación un listado en el que figuran, en orden cronológico, los textos compuestos por el autor desde sus inicios hasta el fin de sus días. Sitúo en primer lugar las composiciones difundidas en periódicos con los que habitualmente colaboraba y a continuación aquellas publicadas en el diario por él mismo dirigido. Junto al título de la composición, señalo la fecha de edición de cada documento y el nombre del periódico que lo hace público. ${ }^{8}$

en estas tablas a pesar de la "pléyade numerosa de buenos escritores dramáticos”, entre los que Hartzenbusch destaca a Morán.

${ }^{8}$ Tan solo incluyo en esta relación los textos que aparecen firmados con el nombre completo del autor o, cuando menos, la inicial de su nombre de pila y el apellido completo; descarto aquellos cuya autoría no podemos adjudicar inequívocamente a Morán por presentar solo como rúbrica la inicial M. o las iniciales J.M. A este respecto, el propio Morán incluye en uno de los números de su periódico una nota informativa en la que advierte a los lectores sobre la posibilidad de confusión en relación con la autoría de determinados artículos debido a la existencia de una firma idéntica a la suya, pero perteneciente a otro escritor, también colaborador asiduo en revistas de la época: "En el número 325 de $E l$ Cascabel [...] hemos leído con gusto una letrilla satírica firmada por J. Morán. Como el director de La Guirnalda viene desde hace muchos años publicando algunos versos con firma idéntica, no nos parece impertinente advertir que el $D$. Jerónimo Morán de nuestro humilde periódico, no es el J. Morán del festivo Cascabel. Mucho agradeceríamos a nuestro cofrade que insertara también en su próximo número esta sencilla aclaración”. (La Guirnalda, i6 agosto, i 867: i 26). Indico la referencia bibliográfica completa. 
- "El ruego", El Artista, I julio, I 836: 5-6.

- "Las catacumbas”, El Guardia Nacional, 26 febrero, i 837: I; La Guirnalda, I6 abril, i 867: 60-6 I .

- "Alfonso Pérez de Vivero. Leyenda castellana del siglo XV", El Panora$m a$, I 8 y 25 julio y I agosto, I 839: 42-45, 6 I-63 y 75-76, respectivamente; La Guirnalda, I 6 diciembre, I 869 y I y I 6 enero, I 870 : 38 I-382, 3-5 y I I-I 2, respectivamente.

- “Lance nocturno", La Risa, 9 junio, I 844: 85; La Guirnalda, I febrero, I 87 I: 2 I 3-2 I 4.

- “A los enamorados”, La Risa, 4 agosto, i 844: I 50- I 5 I.

- "Epístola”, Semanario Pintoresco Español, 6 junio, i 852: 84; La Guirnalda, i6 enero, i 868 : io- i $1 .^{9}$

- “Consejos”, La Guirnalda, I enero, i 867: I-2.

- "Cuento Charada”, La Guirnalda, I enero, i 867: 7-8.

- "Una fábula de Samaniego. Imitación de una anécdota francesa", La Guirnalda, i6 enero, I867: I 2-I 4.

- "Dicha de amor poco dura”, La Guirnalda, i febrero, i 867: i 8-i 9.

- “Imitación de Beranger”, La Guirnalda, I febrero, I 867: 22.

- “A nuestras lectoras”, La Guirnalda, I marzo, i 867: 34.

- "Instinto amoroso. Costumbres de Carnaval”, La Guirnalda, i marzo, I 867: 34-36.

- “Carnes-Tollendas. Romance”, La Guirnalda, I marzo, i 867: 37-39.

- "La ortiga, el niño, la flor. Fábula”, La Guirnalda, i6 marzo, i 867: 42.

- "El guardapiés azul”, La Guirnalda, I abril, i 867: 52-53.

- “A las víctimas del dos de mayo. Romance”, La Guirnalda, I mayo, I 867: 67-68.

- “Para un álbum”, La Guirnalda, i6 mayo, i 867: 76.

- “¡Chis! ¡Chas! Cuento de viejas”, La Guirnalda, I junio, I 867: 85-86.

- "Madrigal”, La Guirnalda, i junio, i 867: 86.

- “La Azucena”, La Guirnalda, i6 junio, i 867: 9 I.

- "Soneto", La Guirnalda, i julio, i 867: 98.

- “La tela de Penélope. Rasgo histórico”, La Guirnalda, i6 julio, I 867: io5-ı06.

- “Endecha”, La Guirnalda, i6 agosto, I 867: г 23.

${ }^{9} \mathrm{La}$ recuperación de este poema en la década de los sesenta incluye como novedad la dedicatoria: "A mi querido amigo el Sr. D.M.R." (La Guirnalda, I6 enero, I 868: Iо). 
- "Risa por llanto", La Guirnalda, 2 septiembre, I 867: I 32.

- “Leyenda morisca”, La Guirnalda, I octubre, i 867: I 48-149.

- “Quejas y Consejos. A D. A. M.”, La Guirnalda, I6 octubre, i 867: I 54 - I 55 .

- "Elvira”, La Guirnalda, 2 noviembre, I 867: ı62-ı63.

- “Artemisa y el mausoleo”, La Guirnalda, 2 noviembre, i 867: i64.

- “Una lección de ortografía”, La Guirnalda, I6 noviembre, i 867: I69I 7 I.

- "Madrigal”, La Guirnalda, i6 noviembre, i 867: I75.

- "Soneto", La Guirnalda, I6 diciembre, I867: I 89.

- "Antorcha de la fe. Breves nociones de historia sagrada. Época primera”, La Guirnalda, I6 enero, I 868: 9- Iо.

- “Epístola. A mi querido amigo el Sr. D. M. R.”, La Guirnalda, I6 enero, I 868 : IO-II.

- "Bibliografía. Corona de la infancia. Lectura poética y canciones para los niños, por la señorita Doña Blanca de Gassó y Ortiz”, La Guirnalda, I 6 enero, I 868: I 2-I 4.

- "Antorcha de la fe. Breves nociones de historia sagrada. Época segunda”, La Guirnalda, I febrero, i 868: i7-i 8 .

- "Perdona, que no era a ti. Letrilla", La Guirnalda, I febrero, i 868: i 9.

- "Los caballeros de industria", La Guirnalda, i febrero, i 868: i 9-2 I.

- "El escollo de la hermosura”, La Guirnalda, i 7 febrero, i 868: 26-28.

- "Epigrama”, La Guirnalda, I7 febrero, i 868: 3 I.

- "Antorcha de la fe. Breves nociones de historia sagrada. Época tercera", La Guirnalda, 2 marzo, I 868: 34-35.

- "Epigrama”, La Guirnalda, 2 marzo, i 868: 39.

- "Antorcha de la fe. Breves nociones de historia sagrada. Época cuarta”, La Guirnalda, I6 marzo, I 868: 41-42.

- “Apólogo”, La Guirnalda, I6 marzo, I 868: 44.

- "En el álbum de Dolores”, La Guirnalda, i abril, I 868 : 53.

- "Antorcha de la fe. Breves nociones sobre historia sagrada. Época quinta”, La Guirnalda, I 6 abril y i junio, I 868: 57-58, 82, respectivamente.

- “Soneto", La Guirnalda, I6 mayo, i 868: 74.

- "Fantasía”, La Guirnalda, I6 mayo, i 868: 76-77.

- "Antorcha de la fe. Breves nociones sobre historia sagrada. Época sexta”, La Guirnalda, I julio, I 868: 97-98. 
- “Cuento”, La Guirnalda, i6 julio, i 868: 107.

- "Antorcha de la fe. Breves nociones de historia sagrada. Época séptima”, La Guirnalda, I y I6 agosto y i septiembre, i 868 : I Io- I I I, I 2 I-I 22 y I 29-I 30, respectivamente.

- "La virtud y el vicio", La Guirnalda, I y I6 septiembre, I 868: I $30-$ I 32 y I 39-I4I, respectivamente. ${ }^{\text {Io }}$

- “Cuento", La Guirnalda, I septiembre, I 868: 132.

- “Biografía. Fray Luis de León”, La Guirnalda, I y I6 octubre, I 868 : I45-I 47 y i 53-I 55, respectivamente.

- "Las doncellas de Simancas", La Guirnalda, I noviembre, I 868: I6 II62.

- "Sobre una tumba”, La Guirnalda, I noviembre, I 868: I62-ı63.

- "David en la tienda de Saúl", La Guirnalda, I6 noviembre, i 868: I69I 70.

- “Cosas de este mundo", La Guirnalda, I diciembre, i 868: I77-I79.

- “El año pasado”, La Guirnalda, I enero, i 869: I 93-i 94.

- “Semíramis", La Guirnalda, I6 enero, I 869: 20 I-202.

- "Letrilla", La Guirnalda, I febrero, I 869: 2 I I-2 2.

- "Bibliografía”, La Guirnalda, i6 febrero, i 869: 223-224.

- “Soneto. (Para un álbum)”, La Guirnalda, i marzo, i 869: 230.

- “Los réprobos. Soneto”, La Guirnalda, I6 marzo, I 869: 236.

- "Pareceres opuestos”, La Guirnalda, i abril, I 869: 245.

- "Los últimos días de Cervantes”, La Guirnalda, i6 abril, i 869: 249$25 \mathrm{I}^{\mathrm{II}}$

- "Las flores de Mayo. Himno dedicado a la Virgen Nuestra Señora”, La Guirnalda, I mayo, I 869: 263.

- "Doctrina de Salomón", La Guirnalda, i 6 junio, i y ı 6 julio, i y i 6 agosto, I 869: 282-283, 29I-292, 300, 306-307 y 3 I 4-3 I 5, respectivamente.

- “En el álbum de Blanca de Gassó”, La Guirnalda, I julio, I 869: 294.

${ }^{10}$ Adjudico la autoría de este cuento a Jerónimo Morán porque, a pesar de que en la rúbrica de la primera parte únicamente figura la inicial M., en la conclusión, recogida en el número siguiente de la publicación, sí aparece su firma completa: “J. Morán”.

${ }^{1}$ Fragmento extraído de su propia obra Biografía de Miguel de Cervantes Saavedra: "Correspondiendo a la actual quincena del mes el aniversario de la muerte del Príncipe de nuestros ingenios, rendimos el presente homenaje a su memoria imperecedera" (La Guirnalda, i6 febrero, I 869: 223). 
- “Soneto. (Improvisado en el Liceo de Valladolid)”, La Guirnalda, I6 septiembre, I 869: 335 .

- “A un niño", La Guirnalda, I octubre, I 869: 338-339.

- "Letrilla", La Guirnalda, i6 noviembre, I 869: 363.

- "Dando unos días", La Guirnalda, i6 diciembre, i 869: 379.

- "Útiles advertencias", La Guirnalda, I6 enero, I 870: 9- го.

- “A Matilde Díez”, La Guirnalda, i febrero, i 870: 22.

- “Los animales con máscaras. Fábula”, La Guirnalda, i 6 febrero, I 870 : 3O-3 . $^{\mathrm{I} 2}$

- "Bibliografía”, La Guirnalda, I abril, i 870: 64-65.

- "La orden de San Jorge o de la Jarretera", La Guirnalda, i6 abril, I 870 : 62.

- "Fabulilla humorística”, La Guirnalda, I mayo, i 870: 68-69.

- "Bibliografía”, La Guirnalda, I6 mayo, i 870: 79.

- "La lección improvisada", La Guirnalda, i6 junio, I 870: 91-93.

- "El que rompe, paga”, La Guirnalda, I octubre, I 870: I48-I49.

- "Soneto", La Guirnalda, I6 octubre, I870: i 58.

- “A mi madre. En una ausencia”, La Guirnalda, I noviembre, i 870: I63.

- “A la Purísima Concepción de Nuestra Señora”, La Guirnalda, I diciembre, I870: I 8 I.

- “Las fatuas de la feria. Cuento", La Guirnalda, I diciembre, I 870: i 82.

- "La festividad de la Candelaria”, La Guirnalda, i febrero, I 87 I: 2092 IO.

- "Exactitud bien entendida", La Guirnalda, I abril, I 87 I: 246-247.

- "El mes de mayo", La Guirnalda, I mayo, I 87 I: 257-258.

- "Barcarola piadosa”, La Guirnalda, i mayo i 87 г: 262.

- “Tú y Yo”, La Guirnalda, i junio, i 87 I: 278.

- "Epigrama”, La Guirnalda, i6 julio, I 87 I: 304.

- "El Ropavejero”, La Guirnalda, I y I6 agosto, I 87 I: 3 I I-3 I 2, 3 I 7-3 I 8.

- "La niña golosa”, La Guirnalda, I septiembre, I 87 I: 322-323. ${ }^{13}$

${ }^{12}$ Antes de aparecer publicado en el periódico del autor, este texto ya había sido difundido, a comienzos de i 868 , por la revista Flor de Infancia en su número cuatro (La Guirnalda, 2 marzo, i $868: 38$ ), al que no he tenido acceso.

${ }^{13}$ Como sucede en el caso de "Los animales con máscaras", también este artículo ve la luz por primera vez en la revista Flor de Infancia (en su número dos), para más tarde ser incorporado a las páginas de La Guirnalda (La Guirnalda, I febrero, I 868: 23). 
- “Ilusiones de la ausencia”, La Guirnalda, I6 septiembre, I 87 I: 33 I-332.

- "Bibliografía. Lecciones familiares. Páginas de la infancia y de la adolescencia”, La Guirnalda, I octubre, I87 I: 343.

- "La coqueta”, La Guirnalda, I6 octubre, i 87 I: 347.

- "El ángel de la poesía. Al malogrado niño Jesús Rodríguez Cao”, La Guirnalda, I6 diciembre, I87I: 38 I.

- “Josefina y Doña Josefa”, La Guirnalda, I6 enero, I 872: I I-I 3.

- “La mujer dentro del cristianismo", La Guirnalda, i febrero, i 872: 20.

- “El baile de doña Aldegundis”, La Guirnalda, I6 febrero, I 872: 28-30.

- "El sermón de diez minutos”, La Guirnalda, I y i6 marzo y I abril, I 872: 33-35, 4I-44, 49-50.

- “A una mariposa”, La Guirnalda, i6 abril, ı 872: 62-63.

- "El dos de mayo de I 808", La Guirnalda, I mayo, I872: I-2.

- "El voto de una madre. Versión libre de una poesía francesa", La Guirnalda, i 6 junio, I 872: 91-92.

- “Baños y aguas minerales”, La Guirnalda, I julio, I 872: 97-98.

- "La manía de los cabellos rubios", La Guirnalda, i6 julio, i 872: го9I IO.

- "El bello ideal. (Escrito para el Liceo de Valladolid)", La Guirnalda, I agosto, I 872: I I6-I I 7 .

- "Bibliografía. El libro de Santoña”, La Guirnalda, I septiembre, i 872: I I 9-I 20.

- “La mujer y el tiempo", La Guirnalda, I6 septiembre, I 872: I 24.

- "Retrato", La Guirnalda, I octubre, I 872: I 32-I 33.

- "Nacimiento de Jesucristo", La Guirnalda, I enero, I 873: I 80. ${ }^{14}$

- "La Fantasía. A mi amigo desde la niñez d. José Zorrilla”, La Guirnalda, I6 enero, I873: 3.

No incluyo en este catálogo el texto $A$ Florinda, anteriormente citado. El periódico Siglo XIX (Madrid I837) recoge en las páginas del número editado ese mismo año una composición de título similar (Florinda), escrita en Valladolid y firmada por un tal M., pero no puedo afirmar con total seguridad que se trate de Jerónimo Morán ni de una obra escrita de su puño

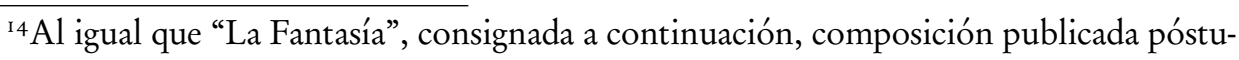
mamente. 
y letra. Tampoco realizo ninguna otra mención al romance morisco Zulma ni al poema Zaida y Gonzalo al no hallar en la prensa decimonónica ningún dato a ellos relativo.

En cuanto a las obras extensas, anoto a continuación sus textos más reconocidos y los que mayor número de menciones obtuvieron en la prensa nacional del momento:

- Zarzuelas:

- El paño de lágrimas.

- La dama blanca.

- Fradiavolo.

- Don Juan de Peralta.

- Aurora la sevillana.

- Candidez y travesura.

- Las damas de la camelia.

- El tren de escala.

- Comedias:

- La ocasión por los cabellos.

- El Príncipe negro. ${ }^{15}$

- Amar a quien se aborrece.

- Dramas:

- Don Ramiro.

- Los cortesanos de don Juan II.

- Biografías:

- Biografía de Mignel de Cervantes Saavedra.

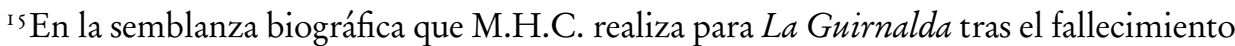
del autor, se incluye esta comedia como obra escrita por Morán: "Muchas son sus obras literarias, pero entre otras, citaremos las comedias La Ocasión por los cabellos y El Príncipe negro, elogiada por todos los críticos que la conocen, y que desearíamos ver en escena en el teatro Español”. (M. H.C., I 873:50). Sin embargo, no he conseguido localizar ninguna otra referencia a esta obra en ninguno de los periódicos de la época. 


\section{BIBLIOGRAFÍA}

Alonso Cortés, Narciso (1914), Antología de poetas vallisoletanos modernos, Valladolid: Biblioteca Studium.

Alonso Seonne, María José et al. (2004), eds., Artículo literario y narrativo breve del romanticismo español, Madrid: Castalia.

Ceide Rodríguez, María (2017), "Arde el reino: Los cortesanos de Juan II y la España de i 868 vistos por La Guirnalda, periódico quincenal dedicado al bello sexo", en Fidel López Criado, ed., El arte en un mundo en crisis. La literatura, el cine y la prensa como instrumentos de transformación social, Santiago de Compostela: Andavira, pp. 24 I-247.

La España Moderna (1913), 29I, marzo, p. 29.

M. C. H. (1 873), "Don Jerónimo Morán”, La Guirnalda, I6 abril, pp. 49-5 I.

Rey Hazas, Antonio y Juan R. Muñoz SánChez (2006), El nacimiento del Cervantismo: Cervantes y el Quijote en el siglo XVIII, Madrid: Verbum Editorial.

Ribao Pereira, Montserrat (20 I7), "Una relectura romántica de la corte: Los cortesanos de don Juan II, de Jerónimo Morán”, en J. M. González Herran et al., eds., La historia en la literatura del siglo XIX. Actas del Coloquio de la Sociedad Española del Siglo XIX, Barcelona: UBE, pp. 65 I-66o.

Rico y Amat, Juan (I 860), Historia politica y parlamentaria de España. Desde los tiempos primitivos hasta nuestros días, Madrid: Imprenta de las Escuelas Pías.

recibido: septiembre de 2018

aceptado: noviembre de 2018 